\title{
Supplementation of Lactobacillus Probiotic Strains Supports Gut- Brain-Axis and Defends Autistic Deficits Occurred by Valproic Acid-Induced Prenatal Model of Autism
}

\author{
K. Sunand ${ }^{1,2, *}$, G. Krishna Mohan', Vasudha Bakshi ${ }^{3}$
}

K. Sunand ${ }^{1,2, *}$, G. Krishna Mohan', Vasudha Bakshi ${ }^{3}$

${ }^{1}$ Centre for Pharmaceutical Sciences, Institute of Science \& Technology, JNTU Hyderabad, INDIA

${ }^{2}$ Department of Pharmacology, Anurag University, Hyderabad, INDIA.

${ }^{3}$ School of Pharmacy, Anurag University, Hyderabad, INDIA.

\section{Correspondence}

\section{K. Sunand}

Centre for Pharmaceutical Sciences,

Institute of Science \& Technology, JNTU Hyderabad; Department of Pharmacology, Anurag University, Hyderabad, INDIA.

Phone no: +91-9000077723;

E-mail: sunandpharmacy@cvsr.ac.in

History

- Submission Date: 18-11-2019;

- Review completed: 07-07-2020;

- Accepted Date: 02-09-2020

DOI : 10.5530/pj.2020.12.226

Article Available online

http://www.phcogj.com/v12/i6s

\section{Copyright}

(C) 2020 Phcogj.Com. This is an openaccess article distributed under the terms of the Creative Commons Attribution 4.0 International license.

\begin{abstract}
Background: Gut microbiota can interact with the brain by bidirectional communication through Gut-Brain-Axis. Gut microbiota colonization is essential for the establishment of symbiotic relation between gut and brain. A healthy gut can properly directs the brain for its functions. Autistic people are deficient in gut microbiota, a condition known as Dysbiosis. Gastro-Intestinal symptoms are comorbid conditions in autism. Re-colonization with daily supplementation of microbiota is needed in autism. Methods: Autism induced by Valproic acid (VPA) at a dose of $400 \mathrm{mg} / \mathrm{kg}$, i.p. on an embryonic day (ED) 12 to the pregnant rats. Born rats exhibited many autistic features, for the treatment we selected specific Lactobacilli strains such as L. Plantarum, L. Casei, L. Acidophilus, L. Bulgaricus, with a dosage of not less than (NLT) 1 Billion Colony-forming units (CFU) /ml given orally every day for 42 days. Results: The results showed that Lactobacillus strains significant ameliorated the behavioral anomalies such as T-Maze, Memory, Social interaction studies as compared to the autistic group. Furthermore, Lactobacillus supplementation helped to shift the hypersertonomia $(27.33 \pm 2.33$ vs 8.167 \pm 0.72$)$, increasesd BDNF $(59.00 \pm 2.08$ vs $48.17 \pm 0.60)$ increased IL-6 $(46.00 \pm 1.52$ vs $32.00 \pm 1.73)$ and TNF- $\alpha$ levels $(145.0 \pm 3.21$ vs $98.67 \pm 2.028)$ to baseline. Histopathology examination of the cerebellum revealed that apoptosis and degeneration were reversed with lactobacillus treatment. Conclusion: This study proved, daily supplementation of Lactobacillus strains has reversed autistic deficits and improved immune functions might because of gut and brain symbiotic relationship.
\end{abstract}

Key words: VPA; Autism; Dysbiosis; Lactobacillus strains; Gut-Brain-Axis.

\section{INTRODUCTION}

Autism is a chronic neurodevelopmental disorder manifested by complex neurobehavioral conditions. ${ }^{1}$ Such as deficient in communication, interaction with people, repetitive movements, behave alone, deficient in motor functions, poor eye contact, etc. ${ }^{2}$ Autism occurs 4-5 times more often in boys than girls. ${ }^{3}$ Possible causes of autism are genetic, environmental factors, maternal toxicity and nutritional deficiency. ${ }^{4}$

Gut and brain have bidirectional communication through the enteric nervous system (ENS) and vagus nerves. Such interactions can be mediated by the metabolites produced by gut bacteria called short chain fatty acids (SCFA) ${ }^{5,6}$ The human gut is inhabited by more than a trillion (approx. $1 \mathrm{~kg}$ ) of gut bacteria (Probiotics) in the right colon. ${ }^{7}$ Gut bacteria have symbiotic co-evolution with the host gut, in return, it improves gut health and functions by (immune support, reduces inflammatory mediators (IL-6, TNF-alpha, etc.), reduces harmful bacteria, production of nutrients and their absorption. ${ }^{8,9}$

Gastrointestinal (GI) symptoms such as abdominal pain, constipation, diarrhea, are common comorbidities with autism. ${ }^{10}$ Evidences related that
GI symptoms are because of dysbiosis of the gut. ${ }^{11}$ At present, there are no effective therapies for autism. A risk-free and effective treatments are necessary for autism. Modulation of the gut microbiota is a potential therapy in people with autism. Prebiotics and probiotics and fecal microbiota transplantation are the various therapeutic opportunities ${ }^{7,11}$.

Probiotics, such as the lactic acid-producing bacteria belonging to Lactobacilli, Bifidobacteria and Saccharomycetes, are beneficial to the host when we provided in adequate quantities. ${ }^{12,13}$ Many studies have shown that probiotics can prevent and treat a variety of diseases, such as obesity, depression, colorectal cancer and Crohn's disease, in animal models and humans. ${ }^{14,15}$

Valproic acid (VPA) is an antiepileptic drug used to treat simple or complex seizures. ${ }^{16}$ Usage of VPA in pregnant women with epilepsy lead risk effects in the fetus such as spina bifida, cleft palate, limb defects and cardiac malformations. ${ }^{17}$ VPA is a potent teratogen, exposure of VPA during the prenatal or postnatal period can serve as triggering factors of oxidative stress which disrupt the neuron growth and development. ${ }^{18}$ With the VPA induced autism model is a valuable tool to investigate the neurobiology, autistic behavior and to screen the several novel therapeutic agents. ${ }^{19}$
Cite this article: Sunand K, Mohan G, Bakshi V. Supplementation of Lactobacillus Probiotic Strains Supports Gut-Brain-Axis and Defends Autistic Deficits Occurred by Valproic AcidInduced Prenatal Model of Autism. Pharmacogn J. 2020;12(6)Suppl:1658-69. 


\section{MATERIALS AND METHODS}

\section{Drugs and chemicals}

Unique Biotech Ltd.: Probiotic strains L. Plantarum- UBLP-40 (MTCC 5380), L. Casei- UBLC-42 (MTCC 5381), L. Acidophilus- UBLA-34 (MTCC 5401), L. Bulgaricus- Lactobacillus bulgaricus UBLB-38; Natures Velvet Lifecare: Inulin (Prebiotic); Sun Pharmaceuticals: Sodium Valproate; Rhetoric India: Rat ELISA Kits (5HT, TNF-alpha, IL-6, BDNF).

\section{Experimental animals}

Pregnant rats at the gestation age procured from the National Institute of Nutrition Hyd. Pregnant animals were maintained on standard laboratory pellet chow diet, provided water ad libitum and were kept under standard conditions at $23-25{ }^{\circ} \mathrm{c}, 35$ to $60 \%$ humidity, and $12 \mathrm{hr}$ light /dark cycle. The experimental protocol was duly approved by Institutional Animal Ethics Committee (IAEC) and care of the animals was carried out as per the guidelines of CPCSEA (Protocol. No: I/IAEC/ AGI/019/2018 WR + ).

\section{Experimental design}

On an embryonic day (ED) 12 administered VPA at a dosage $400 \mathrm{mg} / \mathrm{kg}$, i.p. ${ }^{20}$. The health condition and weight of pregnant rats were monitored regularly until delivery. When the pups were born the day was recorded as postnatal day (PND) 0 . On PND $8^{\text {th }}$ day, rat pups are divided into 7 groups, each group with eight pups $(\mathrm{n}=8)$ namely,

Group I:Vehicle treated group (Inulin 3mg, p.o daily)

Group II : Autistic Group (VPA 400 mg/kg, i.p)

Group III : VPA+L. Plantarum (NLT 1Billion CFU/ml, p.o)

Group IV : VPA+L. Casei (NLT 1Billion CFU/ml, p.o)

Group V : VPA+L. Acidophilus (NLT 1Billion CFU/ml, p.o)

Group VI : VPA+L. Bulgaricus (NLT 1Billion CFU/ml, p.o)

Group VII : VPA+Multilactobacillus strains (NLT 1Billion CFU/ml, p.o).

Multilactobacillus strains are made with a equal proportions of $L$. Plantarum + L. Casei + L. Acidophilus + L. Rhamnosus + L. Bulgaricus strains. The treatment duration for this study was PND 08-50 with daily supplementation of probiotic strains NLT 1 Billion CFU/ml, p.o with the guidelines of administration and storage details provided by Unique Biotech Ltd.

Rats were subjected to behavioral testing to assess Negative geotaxis, Eye-opening, Swimming performance, T-maze, Morris water maze, and Social interaction studies were performed on various postnatal days up to PND 50. All behavioral studies we performed at the Neuroscience lab, School of Pharmacy, Anurag University through a video tracking system provided by VJ Instruments.

\section{BEHAVIORAL STUDIES}

\section{Negative geotaxis}

Negative geotropism was tested on postnatal days $7-10$ by placing the mouse face down along a $45^{\circ}$ incline in a temperature-controlled environment. Latency to turn $180^{\circ}$ such that the head was facing upward along the incline was recorded with a maximum of $30 \mathrm{sec}$ for each trial. ${ }^{19}$

\section{Eye opening}

Eye-opening was observed daily every day after birth PND 12-16. Eye openings were recorded and rated as follows: 0-Both eyes are closed,
1- one eye-opening, 2-Both eyes are opened. ${ }^{19}$

\section{Swimming performance}

An aquarium filled with water $\left(28-29^{\circ} \mathrm{C}\right)$ was used for swimming tests on PNDs 22, 24 and 26. Each animal was put at the center of the aquarium and was observed for 5-10s. The swimming performance was evaluated according to the position of nose and head (angle) on the surface of the water. The angle of swimming was rated as follows: $0-$ head and nose below the surface; 1 -nose below the surface; 2 -nose and top of head at or above the surface but ears still below the surface; 3-the same as two except that water line was at mid-ear level; and 4-the same as three except that water line was at the bottom of ears. Thereafter, the test pups were dried and returned to the home cages. Swimming is a measure of motor development and the integration of a coordinated series of reflex responses. ${ }^{19}$

\section{T-maze test}

The T-maze is a spontaneous alteration test, which was performed on PND 29-31, it is used to evaluate the repetitive/restricted behavior. Five sessions were performed for each rat. For each session, the first choice of the rat in the free choice arms was evaluated, i.e., whether the rat first entered the left or right arms. The parameter analyzed was the percentage of alterations between the left and right arms, which was always assessed in relation to the arm visited in the previous session. This model is based on the natural proclivity of rats to alternate between the visited goal-arms in each trail over a series of successive trails. Thus, a higher percentage of alteration between the arms was considered normal rat behavior, whereas fewer alterations indicated cognitive inflexibility and repeated behavior. For statistical analysis, these data into scores: $0=$ no alterations (repeatedly visiting the same arm for all five sessions), $1=$ one alterations, $2=$ two alterations, $3=$ three alterations, and $4=$ four alterations. ${ }^{21}$

\section{Morris water maze}

Memory was evaluated by Morris water maze, autistic individuals have deficits in memory, and this test was performed on PND 48-50. The aquarium is made up of 4 Quadrants indicated by different colours for visual clues, it was filled with normal water and covered with milk, and a removable hidden platform was placed at one quadrant. Each animal was placed and the escape latency period was recorded, repeat the same for next day PND 49. On PND 50 platform was removed and identify escape latency period. ${ }^{19}$

\section{Social interaction}

Social Interaction was performed on PND 36-40, prior to the experimentation animals are separated and housed individually overnight before the experiment. Two animals from the same group, but different litters were placed into a circular cage provided by ambient light and temperature for $20 \mathrm{~min}$. frequency of the following parameters is assessed: Allogroming, Anogenital Inspections, Pinning's, Play Behavior, Social exploration. ${ }^{17,21}$

\section{Stereotype/ repetitive behavior}

The exploratory behavior of the rat was evaluated by the open-field habituation task method. A rat was placed in a $40 \mathrm{~cm} \times 50 \mathrm{~cm} \times 60 \mathrm{~cm}$ open field whose brown linoleum floor was divided into 12 equal squares by white lines and left to explore it freely for 5 minutes on PND 46-48. The number of line crossings and head dipping was counted. ${ }^{17}$

\section{BIOCHEMICAL PARAMETERS}

Rat brains were isolated and washed with ice-cold $0.1 \mathrm{M}$ phosphate buffer $\mathrm{pH}-7.4$ to remove the blood. Homogenize the brain with $0.1 \mathrm{M}$ 
phosphate buffer saline solution. Then homogenate and the resultant supernatant were used for further biochemical estimations, such as AchE, 5-HT, BDNF, and antioxidants.

\section{Estimation of acetylcholinesterase (AchE) activity}

The AchE activity was measured in brain tissue by the reaction of thiocholine with dithiobisnitrobenzoate ions. The rate of formation of thiocholine from acetylcholine iodide in the presence of brain cholinesterase was measured using a spectrophotometer (Shimadzu 1800) at a wavelength of $412 \mathrm{~nm} \cdot$. $22,23^{2}$

\section{Estimation of BDNF, 5-HT, IL-6 and TNF- a}

The biochemical parameters was measured in the blood and brain sample by ELISA method. To the pre-coated micro ELISA plate samples and standards were added. Then addition of further substrates to conjugate and getting of specific color. The optical density (OD) is measured spectrophotometrically at a wavelength of $450 \mathrm{~nm} \pm 2 \mathrm{~nm}$. The OD value is proportional to the concentration of Rat BDNF, 5-HT, IL- 6 and TNF- $\alpha$. Calculate the concentration of Rat BDNF, 5-HT, IL-6 and TNF- $\alpha$ in the samples by comparing the OD of the samples to the standard curve. ${ }^{24-27}$

\section{HISTOPATHOLOGY}

On PND 50 rats was sacrificed, isolated brains were placed immediately in $10 \%$ neutral formalin solution. Processed and embedded in paraffin. Sagittal sections of the cerebellum $(5 \mu \mathrm{m}$ thick) were stained with hematoxylin and eosin $(\mathrm{H} \& \mathrm{E})$ and analyzed using a light microscope for changes in the cerebellum.

\section{STATISTICAL ANALYSIS}

All data are presented as Mean \pm S.E.M. The significance of difference among the groups was assessed using a one-way analysis of variance (ANOVA) followed by Kolmogorov-Smirnov test, Bonferroni's Multiple Comparison Test using GraphPad Prism 5 software and $(p<$ 0.05 ) was considered significant.

\section{RESULTS}

\section{Behavioral parameters \\ Effect of Lactobacillus strains on negative geotaxis}

There was a significant increase in time taken to re-orient along the inclined plane seen in autistic group on PND 9-21, when compared to vehicle group $(p<0.001)$. Treatment with Lactobacillus strains $(L$. Plantarum, L. Casei, L. Acidophilus, L. Bulgaricus) finally decreased the time taken to re-orient $(p<0.001)$ with the autistic group, the results are shown in Tables $1 \& 2$.

\section{Effect of Lactobacillus strains on Eye-opening}

Delayed eye-opening was seen in the autistic group on PND 1216 compared with the vehicle group $(p<0.001)$. Treatment with Lactobacillus strains (L. Plantarum, L. Casei, L. Acidophilus, L. Bulgaricus) has shown improvement in eye-openings $(p<0.001)$ the results are shown in Figures 1-3.

\section{Effect of Lactobacillus strains on swimming performance}

There was decreased swimming performance in the autistic group compared with the vehicle group $(p<0.001)$. Treatment with Lactobacillus strains (L. Plantarum, L. Casei, L. Acidophilus, L. Bulgaricus) showed improvement in swimming performance $(p<0.001)$ with the autistic group on PND 22, 24 and 26, the results are shown in Figures 4-6.

\section{Effect of Lactobacillus strains on T-maze}

There was a low alteration score reported in the autistic group by the T-maze test on PND 29-31 when compared with the vehicle group $(p<0.001)$. Treatment with Lactobacillus strains (L. Plantarum, $L$. Casei, L. Acidophilus, L. Bulgaricus) showed that alteration score was significantly improved when compared with an autistic group $(p<0.05)$ the results are shown in Figures 7-9.

Table 1: Effect of Lactobacillus strains on Negative geotaxis.

\begin{tabular}{|c|c|c|c|c|}
\hline \multicolumn{5}{|c|}{ Negative geotaxis } \\
\hline Groups & PND 9 & PND 11 & PND 13 & PND 15 \\
\hline Group I (Inulin 3mg, p.o daily) & $1.09 \pm 0.25$ & $1.50 \pm 0.50$ & $3.50 \pm 0.50$ & $2.00 \pm 1.00$ \\
\hline Group II (Autistic group) & $10.0 \pm 0.81 \# \# \#$ & $11.5 \pm 0.50 \# \# \#$ & $12.5 \pm 0.50 \# \# \#$ & $10.57 \pm 0.39 \# \# \#$ \\
\hline Group III (L. Plantarum) & $7.25 \pm 0.86^{* * *}$ & $7.16 \pm 0.28^{\star * *}$ & $6.50 \pm 0.50^{* * *}$ & $7.16 \pm 0.288^{\star * *}$ \\
\hline Group IV (L. Casei) & $7.25 \pm 0.28^{\star * *}$ & $7.00 \pm 0.0^{* * *}$ & $7.33 \pm 0.15^{\star * *}$ & $6.167 \pm 0.28^{\star * \star}$ \\
\hline Group V (L. Acidophilus) & $7.92 \pm 0.15^{*}$ & $7.50 \pm 0.50^{* * *}$ & $6.76 \pm 0.25^{\star * *}$ & $6.033 \pm 0.45^{\star * *}$ \\
\hline Group VI (L. Bulgaricus) & $7.67 \pm 0.53^{* *}$ & $8.16 \pm 0.28^{* * *}$ & $8.33 \pm 0.28^{* * *}$ & $7.23 \pm 0.25^{\star * *}$ \\
\hline Group VII (Multilactobacillus strains) & $6.83 \pm 0.28^{\star * *}$ & $6.83 \pm 0.28^{\star * *}$ & $6.56 \pm 0.92^{\star * *}$ & $6.00 \pm 0.50^{* * *}$ \\
\hline
\end{tabular}

Negative geotaxis in rats with autism. Data expressed as mean $\pm \mathrm{SEM}, \mathrm{n}=6$ for each group. \#\#\#p<0.001 compared to the vehicle. ${ }^{*} p<0.05$, ${ }^{* *} p<0.01,{ }^{* * *} p<0.001$ compared with Autistic group. (Kolmogorov-Smirnov test, Bonferroni's Multiple Comparison Test).

Table 2: Effect of Lactobacillus strains on Negative geotaxis.

\begin{tabular}{cccc}
\hline & \multicolumn{3}{c}{ Negative geotaxis } \\
\hline Groups & PND 17 & PND 19 & PND 21 \\
Group I (Inulin 3mg, p.o daily) & $2.16 \pm 0.288$ & $2.66 \pm 0.57$ & $1.66 \pm 0.76$ \\
Group II (Autistic group) & $10.85 \pm 0.78 \# \# \#$ & $11.17 \pm 1.25 \# \# \#$ & $10.67 \pm 1.04 \# \# \#$ \\
Group III (L. Plantarum) & $6.00 \pm 0.50^{* * *}$ & $5.16 \pm 0.28^{* * *}$ & $4.33 \pm 0.28^{* * *}$ \\
Group IV (L. Casei) & $6.33 \pm 0.28^{* * *}$ & $5.83 \pm 0.28^{* * *}$ & $4.40 \pm 0.173^{* * *}$ \\
Group V (L. Acidophilus) & $5.66 \pm 0.76^{* * *}$ & $6.16 \pm 0.28^{* * *}$ & $5.53 \pm 0.503^{* * *}$ \\
Group VI (L. Bulgaricus) & $7.16 \pm 0.28^{* * *}$ & $6.33 \pm 0.28^{* * *}$ & $5.33 \pm 0.288^{* * *}$ \\
Group VII (Multilactobacillus & $4.90 \pm 0.65^{* * *}$ & $4.66 \pm 0.577^{* * *}$ & $4.16 \pm 0.28^{* * *}$ \\
strains) & &
\end{tabular}

Negative geotaxis in rats with autism. Data expressed as mean $\pm \mathrm{SEM}, \mathrm{n}=6$ for each group. \#\#\#p<0.001 compared to the vehicle. ${ }^{*} p<0.05$, ${ }^{* *} p<0.01,{ }^{* * *} p<0.001$ compared with Autistic group. (Kolmogorov-Smirnov test, Bonferroni's Multiple Comparison Test). 


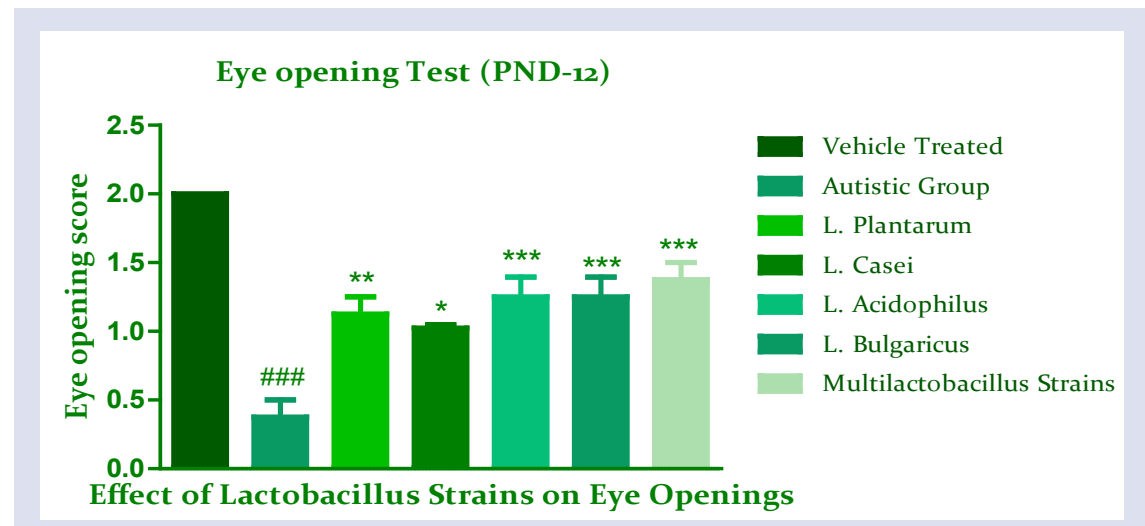

Figure 1: Effect of Lactobacillus strains on Eye openings PND 12

Eye opening test in with autism. Data expressed as mean $\pm S E M, n=6$ for each group. \#\#\# $<0.001$ compared to the vehicle. ${ }^{*} p<0.05,{ }^{* *} p<0.01,{ }^{* * *} p<0.001$ compared with Autistic group. (Kolmogorov-Smirnov test, Bonferroni's Multiple Comparison Test)..
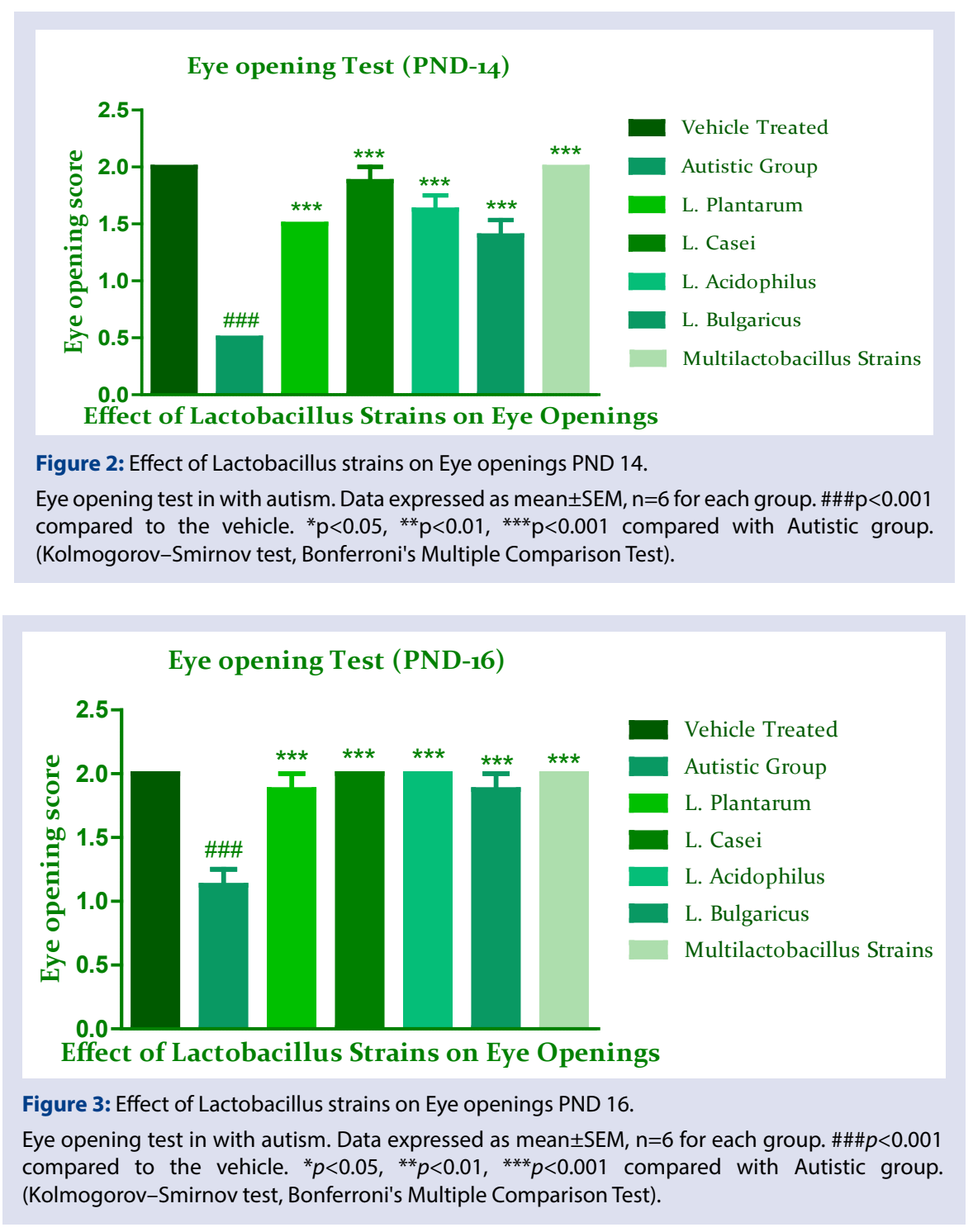

\section{Effect of Lactobacillus strains on Morris water maze}

There was poor cognition seen in the autistic group with the identification of hidden platform on PND 48-50 when compared with the vehicle group $(p<0.001)$. Treatment with Lactobacillus strains $(L$. Plantarum, L. Casei, L. Acidophilus, L. Bulgaricus) showed that latency to identify the hidden platform was significantly increased than autistic subjects $(p<0.001)$ the results are shown in Table 3.

\section{Effect of Lactobacillus strains on Social interaction}

In the autistic group, there was a lower level of social interaction seen when compared to the vehicle group $(p<0.001)$ on PND $36-$ 


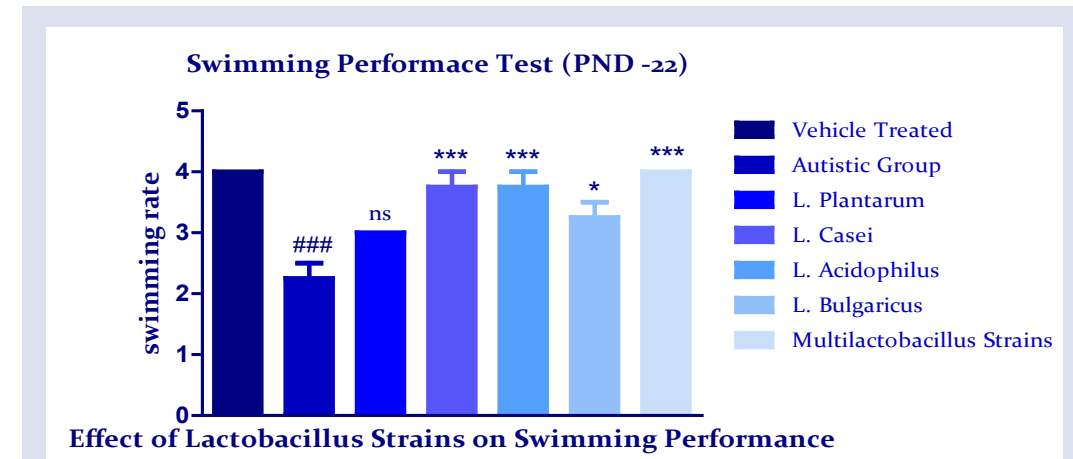

Figure 4: Effect of Lactobacillus strains on swimming performance PND 22.

Swimming performance in rats with autism. Data expressed as mean $\pm S E M, n=6$ for each group. \#\#\#p<0.001 compared to the vehicle. ${ }^{*} p<0.05,{ }^{* *} p<0.01,{ }^{* * *} p<0.001$ compared with Autistic group. (Kolmogorov-Smirnov test, Bonferroni's Multiple Comparison Test).
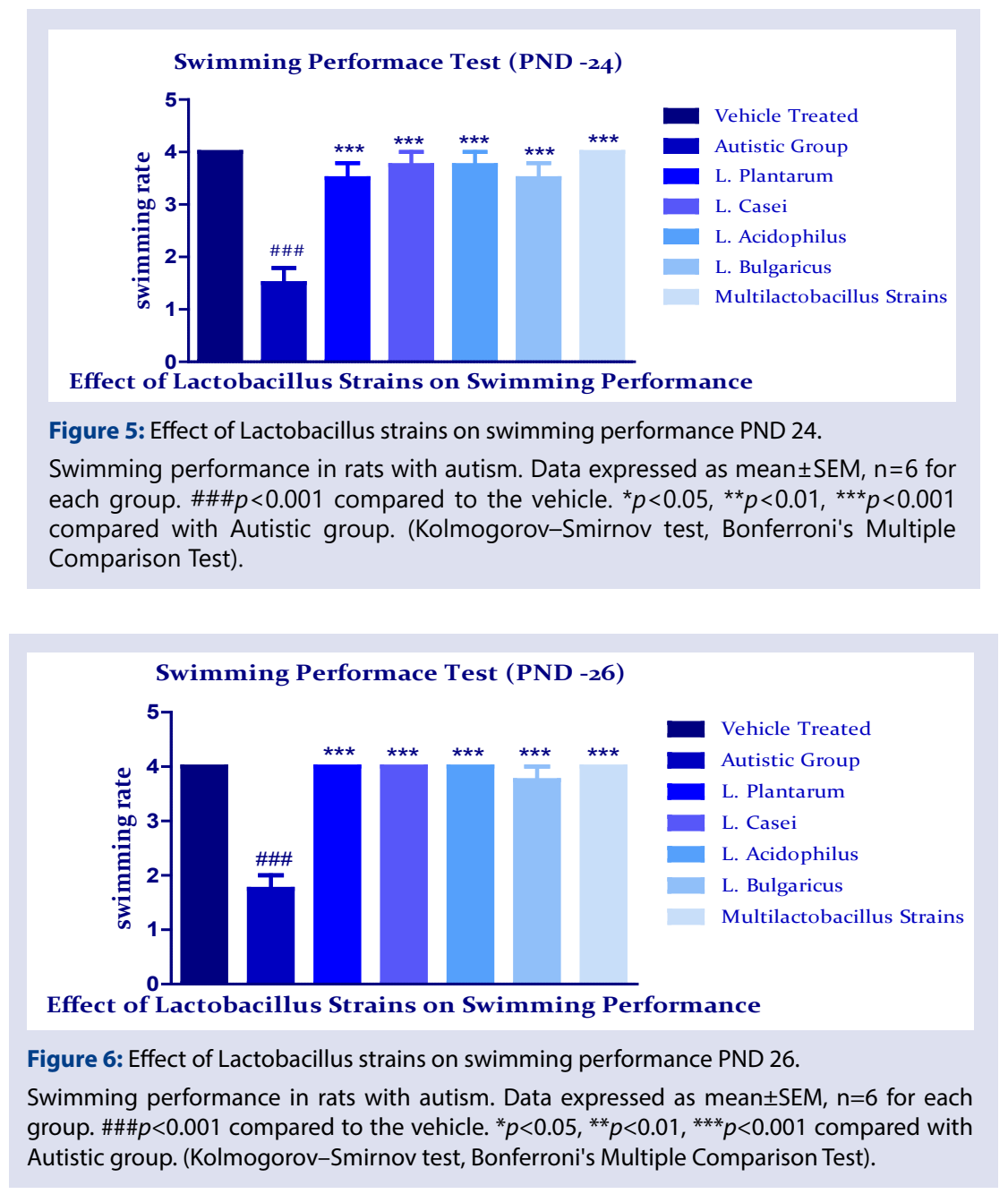

40. Treatment with Lactobacillus strains (L. Plantarum, L. Casei, L. Acidophilus, L. Bulgaricus) shown improvement in all social interaction activities $(p<0.001)$ when compared with the autistic group. The results are shown in Table 4.

\section{Effect of Lactobacillus strains on Repetitive/Stereotype Behavior}

There was a decrease in exploration and nature of behavior in autistic rats when compared with the vehicle group $(p<0.001)$ on PND 4648. Treatment with Lactobacillus strains (L. Plantarum, L. Casei, L. Acidophilus, L. Bulgaricus) improved their stereotype behavior $(p<0.001)$ when compared with the autistic group. The results are shown in Table 5.

\section{Biochemical parameters}

\section{Estimation of IL-6 \& TNF-a}

Prenatal induction of autism resulted in significant increase in IL-6 \& TNF- $\alpha$ levels $(p<0.001)$ when compared with the vehicle group. Lactobacillus strains treatment significantly attenuated the increased IL-6 \& TNF-a levels $(p<0.001)$ when compared with the autistic group. The results are shown in Table 6 . 


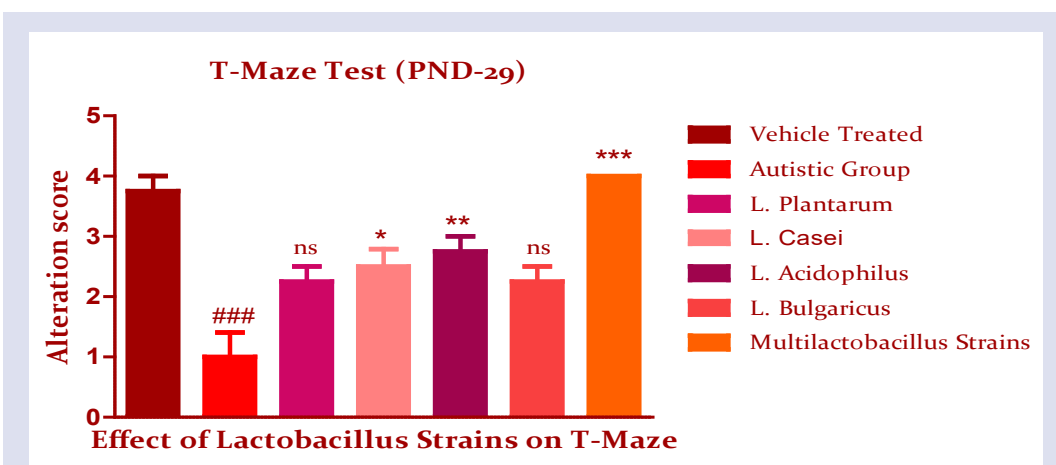

Figure 7: Effect of Lactobacillus strains on T-Maze PND 29.

$\mathrm{T}$-maze test in rats with autism. Data expressed as mean $\pm S E M, n=6$ for each group. $\# \#$ \# $<0.001$ compared to the vehicle. ${ }^{*} p<0.05,{ }^{* *} p<0.01,{ }^{* * *} p<0.001$ compared with Autistic group. (Kolmogorov-Smirnov test, Bonferroni's Multiple Comparison Test).

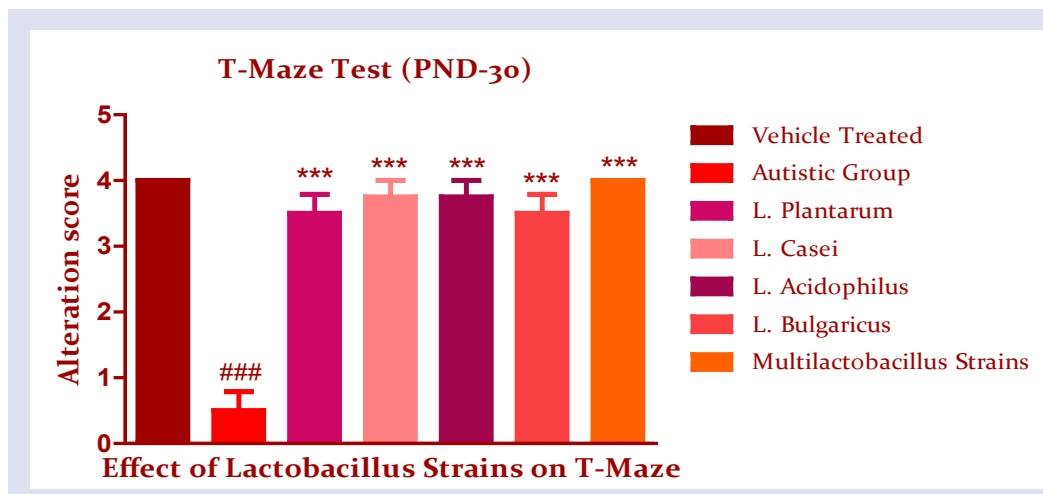

Figure 8: Effect of Lactobacillus strains on T-Maze PND 30

T-maze test in rats with autism. Data expressed as mean $\pm S E M, n=6$ for each group. $\# \# \#<0.001$ compared to the vehicle. ${ }^{*} p<0.05,{ }^{* *} p<0.01$, ${ }^{* * *} p<0.001$ compared with Autistic group. (Kolmogorov-Smirnov test, Bonferroni's Multiple Comparison Test).

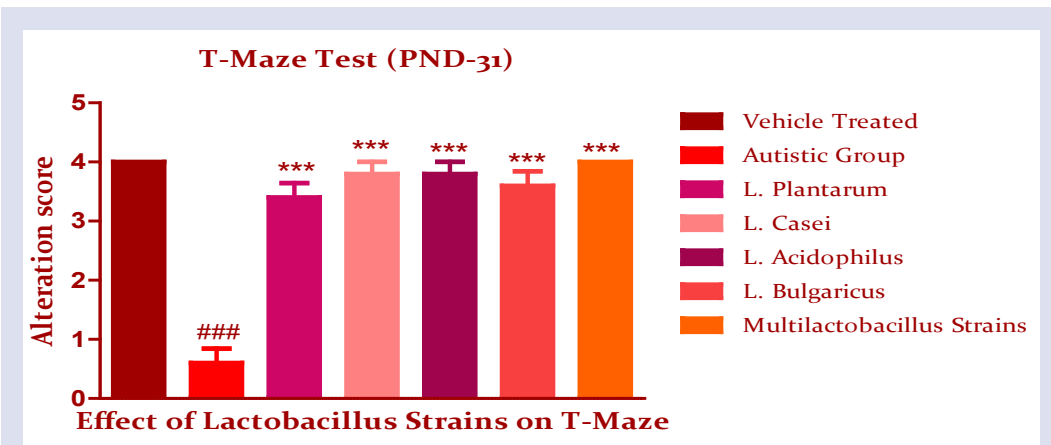

Figure 9: Effect of Lactobacillus strains on T-Maze PND 31.

T-maze test in rats with autism. Data expressed as mean $\pm S E M, n=6$ for each group. $\# \#$ \# $<0.001$ compared to the vehicle. ${ }^{*} p<0.05,{ }^{* \star} p<0.01,{ }^{* * \star} p<0.001$ compared with Autistic group. (Kolmogorov-Smirnov test, Bonferroni's Multiple Comparison Test).

Table 3: Effect of Lactobacillus strains on Memory test (Morris water maze).

\begin{tabular}{cccc}
\hline & Morris water maze & & \\
\hline Groups & PND 48 & PND 49 & PND 50 \\
Group I (Inulin 3mg, p.o daily) & $50.25 \pm 3.750$ & $40.00 \pm 2.88$ & $14.00 \pm 0.57$ \\
Group II (Autistic group) & $137.0 \pm 6.69 \# \# \#$ & $146.7 \pm 17.64 \# \# \#$ & $122.7 \pm 7.21 \# \# \#$ \\
Group III (L. Plantarum) & $79.25 \pm 2.49^{* * *}$ & $56.67 \pm 4.41^{* * *}$ & $26.67 \pm 3.33^{* * *}$ \\
Group IV (L. Casei) & $80.50 \pm 2.10^{* * *}$ & $48.00 \pm 1.52^{* * *}$ & $25.00 \pm 3.33^{* * *}$ \\
Group V (L. Acidophilus) & $72.00 \pm 2.12^{* * *}$ & $31.67 \pm 1.66^{* * *}$ & $16.67 \pm 4.41^{* * *}$ \\
Group VI (L. Bulgaricus) & $81.75 \pm 1.65^{* * *}$ & $55.00 \pm 2.88^{* * *}$ & $26.67 \pm 1.66^{* * *}$ \\
Group VII (Multilactobacillus strains) & $61.50 \pm 2.53^{* * *}$ & $23.33 \pm 4.41^{* * *}$ & $9.66 \pm 1.202^{* * *}$ \\
\hline
\end{tabular}

Memory test (Morris water maze) in rats with autism. Data expressed as mean $\pm \mathrm{SEM}, \mathrm{n}=6$ for each group. \#\#\#p<0.001 compared to the vehicle. ${ }^{*} p<0.05,{ }^{* *} p<0.01,{ }^{* * *} p<0.001$ compared with Autistic group. (Kolmogorov-Smirnov test, Bonferroni's Multiple Comparison Test). 
Table 4: Effect of Lactobacillus strains on Social interaction.

\begin{tabular}{|c|c|c|c|c|c|}
\hline \multicolumn{6}{|c|}{ Social interaction } \\
\hline Groups & Allogrooming & Anogenital inspection & Pinnings & Play behavior & Social exploration \\
\hline Group I (Inulin 3mg, p.o daily) & $13.52 \pm 0.33$ & $27.50 \pm 1.04$ & $20.75 \pm 1.25$ & $8.66 \pm 0.33$ & $21.50 \pm 0.64$ \\
\hline Group II (Autistic group) & $2.25 \pm 0.85 \# \# \#$ & $9.25 \pm 1.109 \# \# \#$ & $8.250 \pm 1.65 \# \# \#$ & $1.00 \pm 0.57 \# \# \#$ & $8.75 \pm 0.85 \# \# \#$ \\
\hline Group III (L. Plantarum) & $6.00 \pm 0.40^{* *}$ & $16.00 \pm 0.40^{* * *}$ & $14.00 \pm 0.91^{* *}$ & $4.00 \pm 0.57^{\star}$ & $12.50 \pm 0.28^{*}$ \\
\hline Group IV (L. Casei) & $11.25 \pm 0.47^{\star * *}$ & $17.50 \pm 0.28^{\star * *}$ & $15.75 \pm 0.47^{\star * *}$ & $4.66 \pm 0.66^{* *}$ & $14.75 \pm 0.28^{\star * *}$ \\
\hline Group V (L. Acidophilus) & $12.00 \pm 0.40^{* * *}$ & $22.00 \pm 0.91^{\star * *}$ & $16.50 \pm 1.04^{* * *}$ & $5.00 \pm 0.57^{\star *}$ & $12.75 \pm 0.62^{*}$ \\
\hline Group VI (L. Bulgaricus) & $7.750 \pm 0.47^{\star * *}$ & $14.00 \pm 0.40^{\star *}$ & $14.00 \pm 0.40^{\star *}$ & $4.33 \pm 0.33^{\star *}$ & $13.50 \pm 1.04^{\star *}$ \\
\hline Group VII (Multilactobacillus strains) & $12.50 \pm 0.64$ & $24.00 \pm 0.48^{* * *}$ & $17.25 \pm 0.47^{\star * *}$ & $8.00 \pm 0.57^{* * *}$ & $17.50 \pm 0.64^{* * *}$ \\
\hline
\end{tabular}

Social interaction in rats with autism. Data expressed as mean $\pm \mathrm{SEM}, \mathrm{n}=6$ for each group. \#\#\#p<0.001 compared to the vehicle. ${ }^{*} p<0.05,{ }^{* *} p<0.01,{ }^{* * *} p<0.001$ compared with Autistic group. (Kolmogorov-Smirnov test, Bonferroni's Multiple Comparison Test).

Table 5: Effect of Lactobacillus strains on repetitive/stereotypic-like behaviors.

\begin{tabular}{|c|c|c|c|}
\hline \multicolumn{4}{|c|}{ Repetitive/stereotypic-like behaviors } \\
\hline Groups & Rearing's & Grooming & Hole pocking \\
\hline Group I (Inulin 3mg, p.o daily) & $24.50 \pm 0.64$ & $15.00 \pm 1.08$ & $20.00 \pm 1.08$ \\
\hline Group II (Autistic group) & $7.25 \pm 0.47 \# \# \#$ & $6.75 \pm 0.62 \# \# \#$ & $9.75 \pm 0.85 \# \# \#$ \\
\hline Group III (L. Plantarum) & $12.75 \pm 0.62^{\star * \star}$ & $10.25 \pm 0.47^{\star}$ & $15.75 \pm 0.47^{\star * *}$ \\
\hline Group IV (L. Casei) & $14.50 \pm 0.28^{\star * *}$ & $10.75 \pm 0.47^{\star *}$ & $15.25 \pm 1.03^{* * *}$ \\
\hline Group V (L. Acidophilus) & $16.50 \pm 0.28^{\star * *}$ & $12.50 \pm 0.50^{* * *}$ & $16.50 \pm 0.64^{* * *}$ \\
\hline Group VI (L. Bulgaricus) & $13.50 \pm 1.04^{* * *}$ & $10.50 \pm 0.47^{\star}$ & $13.50 \pm 0.28^{*}$ \\
\hline Group VII (Multilactobacillus strains) & $19.25 \pm 0.85^{* * *}$ & $13.50 \pm 0.64^{* * *}$ & $18.50 \pm 0.64^{* * *}$ \\
\hline
\end{tabular}

Repetitive/stereotypic-like behaviors in rats with autism. Data expressed as mean $\pm \mathrm{SEM}, \mathrm{n}=6$ for each group. \#\#\#p<0.001 compared to the vehicle. ${ }^{*} p<0.05,{ }^{* *} p<0.01,{ }^{* * *} p<0.001$ compared with Autistic group. (Kolmogorov-Smirnov test, Bonferroni's Multiple Comparison Test).

Table 6: Effect of Lactobacillus strains on proinflammatory cytokines levels.

\begin{tabular}{|c|c|c|}
\hline \multicolumn{3}{|c|}{ Proinflammatory cytokines } \\
\hline Groups & IL-6 (pg/ml) & TNF- $a(p g / m l)$ \\
\hline Group I (Inulin 3mg, p.o daily) & $25.67 \pm 1.764$ & $89 \pm 3.64$ \\
\hline Group II (Autistic group) & $46.00 \pm 1.528 \# \# \#$ & $145.0 \pm 3.215 \# \# \#$ \\
\hline Group III (L. Plantarum) & $29.00 \pm 0.577^{\star * *}$ & $107.3 \pm 3.383^{* * *}$ \\
\hline Group IV (L. Casei) & $30.17 \pm 0.6009^{* * *}$ & $111.7 \pm 2.028^{* * *}$ \\
\hline Group V (L. Acidophilus) & $33.50 \pm 0.2889^{* * *}$ & $124.7 \pm 0.88^{\star *}$ \\
\hline Group VI (L. Bulgaricus) & $36.67 \pm 1.202^{* *}$ & $115.3 \pm 3.283^{* * *}$ \\
\hline Group VII (Multilactobacillus strains) & $32.00 \pm 1.732^{\star * *}$ & $98.67 \pm 2.028^{* * *}$ \\
\hline
\end{tabular}

Proinflammatory cytokines levels in rats with autism. Data expressed as mean $\pm \mathrm{SEM}, \mathrm{n}=6$ for each group. \#\#\#p<0.001 compared to the vehicle. ${ }^{*} p<0.05,{ }^{* *} p<0.01,{ }^{* * *} p<0.001$ compared with Autistic group. (Kolmogorov-Smirnov test, Bonferroni's Multiple Comparison Test).

Table 7: Effect of Lactobacillus strains on BDNF, 5-HT, AchE.

\begin{tabular}{cccc}
\hline & \multicolumn{2}{c}{ BDNF, 5-HT, AchE } & \\
\hline Groups & BDNF $(\mathrm{pg} / \mathrm{ml})$ & 5-HT $(\mathrm{ng} / \mathrm{ml})$ & AchE $(\mu \mathrm{M} / \mathrm{min} / \mathrm{mg}$ tissue $)$ \\
\hline Group I (Inulin 3mg, p.o daily) & $45.00 \pm 1.55$ & $5.267 \pm 0.318$ & $1.30 \pm 0.15$ \\
Group II (Autistic group) & $59.00 \pm 2.082 \# \# \#$ & $27.33 \pm 2.33 \# \# \#$ & $7.15 \pm 0.38 \# \#$ \\
Group III (L. Plantarum) & $49.33 \pm 0.88^{* * *}$ & $16.00 \pm 1.00^{* * *}$ & $2.254 \pm 0.25^{* * *}$ \\
Group IV (L. Casei) & $46.17 \pm 0.44^{* * *}$ & $9.33 \pm 0.881^{* * *}$ & $3.25 \pm 0.47^{* * *}$ \\
Group V (L. Acidophilus) & $50.00 \pm 0.577^{* *}$ & $15.67 \pm 0.88^{* * *}$ & $3.69 \pm 0.34^{* * *}$ \\
Group VI (L. Bulgaricus) & $49.00 \pm 1.525^{* * *}$ & $12.67 \pm 0.667^{* * *}$ & $5.20 \pm 0.44^{* *}$ \\
Group VII (Multilactobacillus & $48.17 \pm 0.60^{* * *}$ & $8.167 \pm 0.72^{* * *}$ & $1.33 \pm 0.144^{* * *}$ \\
\hline
\end{tabular}

BDNF, 5-HT, AchE levels in rats with autism. Data expressed as mean \pm SEM, $\mathrm{n}=6$ for each group. \#\#\# $<<0.001$ compared to the vehicle. ${ }^{*} p<0.05$, ${ }^{* *} p<0.01,{ }^{* *} p<0.001$ compared with Autistic group. (Kolmogorov-Smirnov test, Bonferroni's Multiple Comparison Test). 


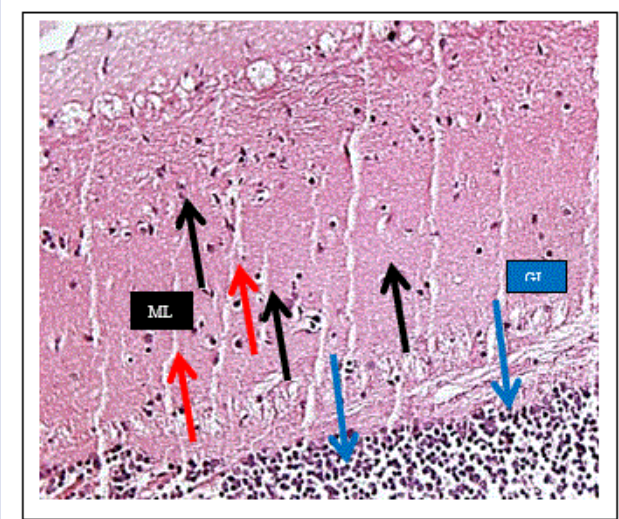

a) Vehicle treated group

- Black arrow: Normal Molecular layer of cerebellum - Red arrow: Capillary

- Blue arrow: Granular layer of cerebellum

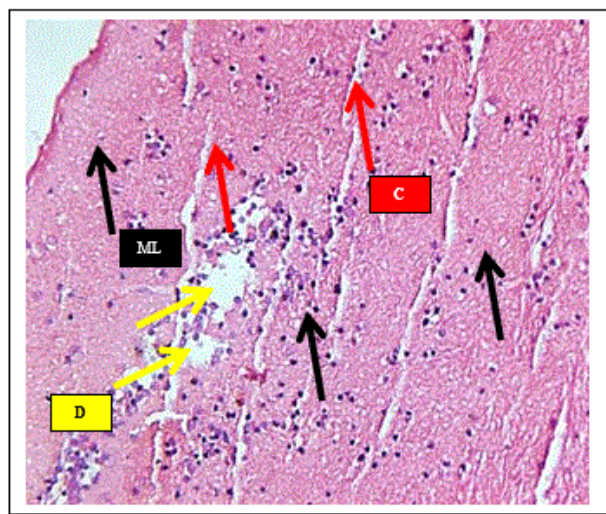

c) L. Plantarum group

-Black arrow: Normal Molecular layer of cerebellum

- Red arrow: Capillary

- Yellow arrow: Mild vacuolar degeneration of neurons

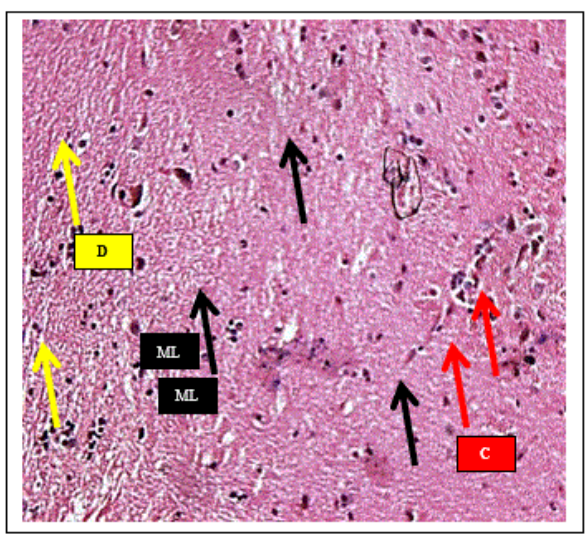

e) L. Acidophilus group

- Black arrow: Normal Molecular layer of cerebellum

- Red arrow: Capillary

- Yellow arrow: Mild vacuolar degeneration of neurons

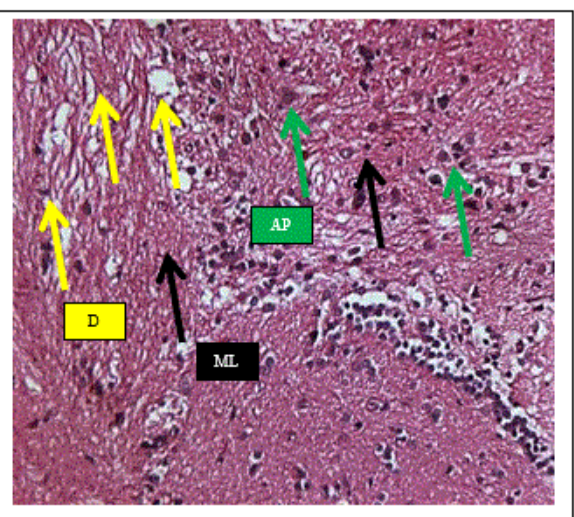

b) Autistic group|

Black arrow: Molecular layer not appeared normal Green arrow: Apoptosis of many neurons Yellow arrow: Damaged neurons

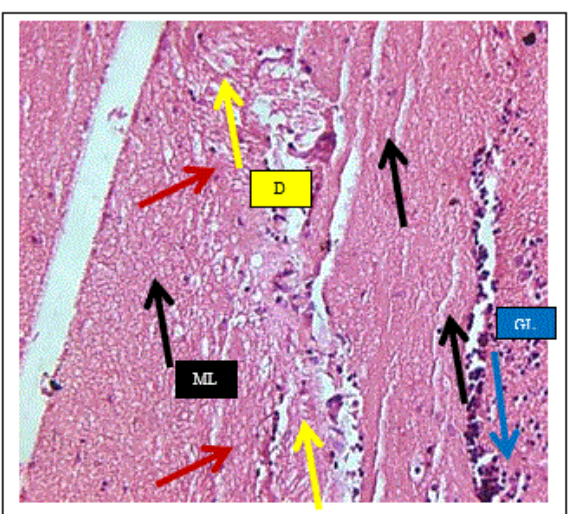

d) L. Casei group

Black arrow: Molecular layer appeared normal Brown arrow: Recovering of neurons Yellow arrow: Damaged neurons

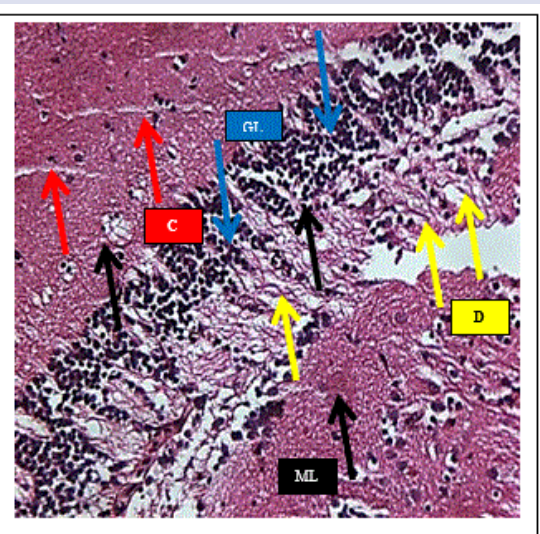

f) L. Bulgaricus group

Black arrow: Molecular layer appeared normal Brown arrow: Recovering of neurons Yellow arrow: Damaged neurons 


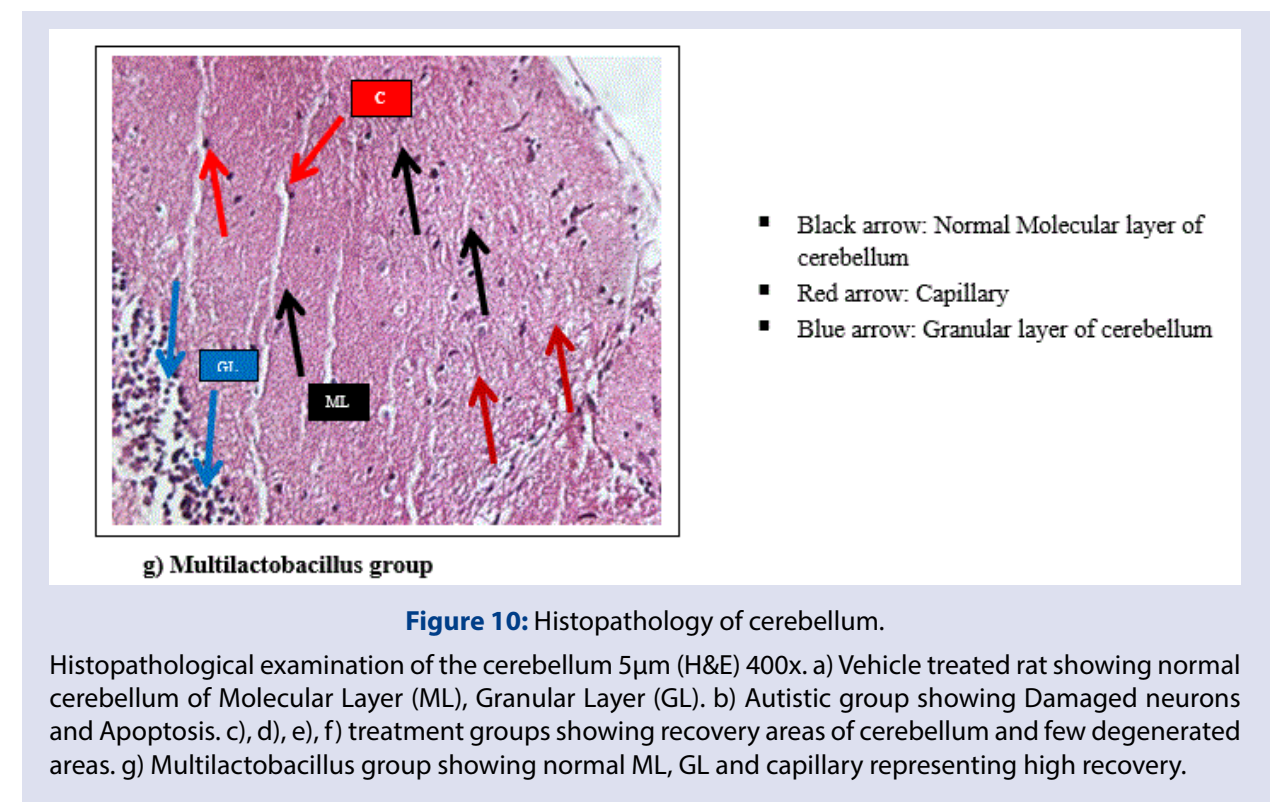

\section{Estimation of BDNF}

Significantly elevated levels of BDNF were seen in autistic group $(p<0.001)$ when compared with the vehicle group. Lactobacillus strains treatment decreased the BDNF levels $(p<0.001)$ when compared with the autistic group. The results are shown in Table 7.

\section{Estimation of $5 \mathrm{HT}$}

Autistic rats have shown hypersertonomia when compared with the vehicle group $(p<0.001)$. Lactobacillus strains treatment significantly decreased serotonin levels activity $(p<0.001)$ when compared with the autistic group. The results are shown in Table 7.

\section{Effect of Lactobacillus strains on AChE levels}

In the autistic group increased acetylcholinesterase activity seen when compared with the vehicle group $(p<0.001)$. Lactobacillus strains treatment significantly attenuated the increased enzyme activity $(p<0.001)$ when compared with the autistic group. The results are shown in Table 7.

\section{DISCUSSION}

According to the results of this study, prenatal model of autism resulted in delayed delivery, low birth weight of pups and behavioral anomalies. The lactobacillus strains treatment ameliorated the autistic like behaviors. The offspring who exposed to VPA in the uterus showed impairment in social interaction, memory and other behavioral tests.

Negative geotaxis is an assessment parameter to motor performance of cerebellum. In autistic group increase time to reorient on the inclined plane. ${ }^{19,28,29}$. Reorientation time was decreased by lactobacilli. There was a delay in Eye-openings in autistic rats ${ }^{19}$ on PND 12-16, which were become normal in the lactobacillus treatment.

Swimming performance was evaluated to measure motor development. Lower swimming activity is seen in autistic group ${ }^{19,30}$. Swimming rate was improved in lactobacillus treatment from PND 24 onwards. Hippocampus essential in spatial memory and learning behavior. In the T-maze test lack of spontaneous alterations is observed in the autistic group ${ }^{1}$. With the lactobacillus treatment it re-established the spontaneous alteration.

Morris water maze test an important tool to assess the cognitive ability. Autistic group increased latency to swim and identification of hidden platform is seen ${ }^{19}$. With lactobacillus treatment improved navigation skills and memory performance contributing its impact on Gut-Brain communication.

One of the important confirmation test for autism is social interaction. This test is used to assess the different patterns of behavior, communication and play behavior. With the results social interaction studies in rats were similar to autistics. In our study we identified impairments of play behavior, pinning, social explorations and repetitive behavior become normal with the autistic subjects. ${ }^{1,19,30}$.

Cytokines including TNF- $\alpha$, IFN- $\gamma$, IL- $1 \beta$, and IL- 6,12 have been reported to be elevated in the blood of autistic subjects ${ }^{31}$. In the CNS IL- 6 can trigger inflammation and demyelination ${ }^{32}$. Our study evaluated the levels of TNF- $\alpha$ in serum, IL- 6 in the cerebellum. In autistic animals IL- 6 and TNF- $\alpha$ levels were increased with the lactobacillus treatment IL- 6 and TNF- $\alpha$ activity become normal by their immune supportive mechanisms $^{33,34}$.

BDNF is a neurotrophic factor (NF) that supports the growth, survival of developing and mature neurons of cholinergic, dopaminergic, and serotonergic neurons ${ }^{35}$. NF is more active in the hippocampus, cortex, and forebrain involved in learning, memory and higher thinking. In our study increased BDNF levels seen in serum of autistic subjects ${ }^{36,37}$. Treatment with lactobacillus strains BDNF activity normal with that of vehicle group.

Hyperseretonomia is seen in $25-50 \%$ autistic cases, hyperserotonemia is considered to be one of the most-well replicated findings in neurobiology ${ }^{38} 5$-HT or Serotonin is originated in the gut has a pivotal role in Gut-Brain communication. Some biological factors that cause the platelet hyperserotonemia may play a role in the early development of the autistic brain..$^{39,40}$ in our study we examined hyperseretonomia ${ }^{41,42}$ in autistic group treatment with lactobacillus strains attenuated the hyperseretonomia condition, improved social behavior and communication by attributing to its effect on balancing 5 -HT release from gut.

Acetylcholine is involved in the learning and memory, acetylcholine (ACh) in the synaptic cleft by hydrolysed by acetylcholinesterase (AChE). ${ }^{43}$ A good level of acetylcholine has a regulating role in attention, cognition, social interactions and stereotypical behaviors. ${ }^{44-47}$ in results due to excessive oxidative stress by VPA up-regulation of acetylcholinesterase seen in the autistic group. ${ }^{48}$ Treatment with 
lactobacillus strains significantly decreased AchE levels by attenuating the enzyme activity.

Histopathology results of cerebellum reveals damage and apoptosis of molecular layer, granular layer seen in the autistic group. ${ }^{28}$ Treatment with lactobacillus strains reveals mild degeneration, few necrotic cells reported in L. Plantarum and L. Bulagricus. Cerebellum become normal is seen L. Acidophilus and L. Casei and Multilactobacillus strain treatment groups. The recovery of cerebellum providing an important link connecting probiotics role in Gut and Brain communication, immune and brain health support.

\section{CONCLUSION}

In conclusion, by comparing all behavioral and biochemical results and histopathology of the cerebellum, It can be emphasized that daily supplementation with Lactobacillus strains provides a healthy gut by the enrichment of microbial diversity and re-colonization of useful bacteria that can be able to alter the brain functionality by Gut-Brain-Axis. Among we studied for four lactobacillus strains, $L$. Acidophilus and $L$. Casei given potential outcomes in recovering autism. Multilactobacillus combination is more approachable therapy, it can advances the benefit of probiotic treatment. According to our results, daily supplementation of Lactobacillus is very effective in the recovery of autism associated Dysbiosis. The present findings of this research work contributing to an important understanding on influence of gut microbiota on brain health. Further our studies will continue on selected probiotic strains of Bifidobacterium, Saccharomyces, Streptococcus and their combination with potent natural drugs.

\section{HIGHLIGHTS}

- VPA at a dose of $400 \mathrm{mg} / \mathrm{kg}$, i.p. on ED 12 to the pregnant rats has induced autism in born rats.

- Lactobacillus strains (L. Plantarum, L. Casei, L. Acidophilus, L. Bulgaricus) with good potential health benefits are selected for the study.

- Daily supplementation with Lactobacillus strains NLT 1 Billion $\mathrm{CFU} / \mathrm{ml}$ ameliorated the Behavioral \& Biochemical deficits.

- Lactobacillus has proven its therapeutic efficacy in autism-associated dysbiosis.

\section{ACKNOWLEDGMENT}

We are sincerely thankful for UNIQUE BIOTECH LTD. for their kind support for providing all Lactobacillus strains. Also, we express sincere gratitude towards Chairman - Dr. Palla Rajeshwar Reddy, Dean - Dr. Vasudha Bakshi, School of Pharmacy, and Anurag University for their support in research.

\section{REFERENCES}

1. Cezar, L. C., Kirsten, T. B., da Fonseca, C. C. N., de Lima, A. P. N., Bernardi,M.M.,andFelicio, L. F. (2018). Zinc as a therapy in a rat model of autism prenatally induced by valproic acid. Prog. Neuropsychopharmacol. Biol. Psychiatry 84, 173-180.

2. Gonzales, E. L. T., Jang, J. H., Mabunga, D. F. N., Kim, J. W., Ko, M. J., Cho, K. S., Bahn, G. H., Hong, M., Ryu, J. H., Kim, H. J., Cheong, J. H., \& Shin, C. Y. (2016). Supplementation of Korean Red Ginseng improves behavior deviations in animal models of autism. Food and Nutrition Research, 60, [29245].

3. Baio, J., Wiggins, L., Christensen, D. L., Maenner, M. J., Daniels, J.,Warren, Z., et al. (2018). Prevalence of autism spectrum disorder among children aged 8 years - autism and developmental disabilities monitoring network, 11 sites, United States, 2014. MMWR Surveill. Summ. 67, 1-23.

4. Bromley RL, Mawer GE, Briggs M, Cheyne C, Clayton-Smith J, et al. (2013) The prevalence of neurodevelopmental disorders in children prenatally exposed to antiepileptic drugs. J Neurol Neurosurg Psychiatry 84: 637-643.

5. Mangiola F, laniro G, Franceschi F, Fagiuoli S, Gasbarrini G, Gasbarrini A. Gut microbiota in autism and mood disorders. World J Gastroenterol. 2016;22(1):361-368
6. Luna RA, Savidge TC, Williams KC. The Brain-Gut-Microbiome Axis: What Role Does It Play in Autism Spectrum Disorder. Curr Dev Disord Rep. 2016;3(1):7581.

7. Li Q, Zhou JM. The microbiota-gut-brain axis and its potential therapeutic role in autism spectrum disorder. Neuroscience. 2016;324:131-139.

8. Mayer EA, Padua D, Tillisch K. Altered brain-gut axis in autism: comorbidity or causative mechanisms. Bioessays. 2014;36(10):933-939.

9. Rosenfeld CS. Microbiome Disturbances and Autism Spectrum Disorders Drug Metab Dispos. 2015;43(10):1557-1571.

10. Wang M, Zhou J, He F, et al. Alteration of gut microbiota-associated epitopes in children with autism spectrum disorders. Brain Behav Immun. 2019;75:192199

11. Petra Al, Panagiotidou S, Hatziagelaki E, Stewart JM, Conti P, Theoharides TC Gut-Microbiota-Brain Axis and Its Effect on Neuropsychiatric Disorders with Suspected Immune Dysregulation. Clin. Ther. 2015;37(5):984-995.

12. Verna E. C., Lucak S. (2010). Use of probiotics in gastrointestinal disorders: what to recommend. Therap. Adv. Gastroenterol. 3, 307-319.

13. Verma A., Shukla G. (2014). Synbiotic (Lactobacillus rhamnosus+Lactobacil usacidophilus+inulin) attenuates oxidative stress and colonic damage in 1, 2 dimethylhydrazinedihydrochloride-induced colon carcinogenesis in SpragueDawley rats: a long-term study. Eur. J. Cancer Prev. 23, 550-559.

14. Valsecchi C., Carlotta T. S., Castellazzi A. (2016). Gut microbiota and obesity. J. Clin. Gastroenterol. 50(Suppl. 2), 13-15, 2015, S157-S158.

15. Sharma M., Shukla G. (2016). Metabiotics: one step ahead of probiotics; an insight into mechanisms involved in anticancerous effect in colorectal cancer. Front. Microbiol 7:1940.

16. Browne TR, Valproic acid. N Engl J Med. 1980; 302:661-666.

17. Kini U. Fetal valproate syndrome: a review. Paediatr Perinat Drug Therapy. 2006 7(3):123-130.

18. Ming, X., Cheh, M.A., Halladay, A.K., Wagner, G.C., 2008. Evidence of oxidative stress in autism derived from animal models. Am.J. Biochem. Biotechnol. 4 , 218-225.

19. Schneider, T., Przewłocki, R. Behavioral alterations in rats prenatally exposed to valproic acid: an animal model of autism. Neuropsychopharmacology. 2005; 30, 80-89

20. Liu, F., Horton-Sparks, K., Hull, V. et al. The valproic acid rat model of autism presents with gut bacterial dysbiosis similar to that in human autism. Molecular Autism 9, 61 (2018).Schneider, T., Przewłocki, R. Behavioral alterations in rats prenatally exposed to valproic acid: an animal model of autism. Neuropsychopharmacology. 2005; 30, 80-89.

21. Ellman,.L.,Courtney, K.D.,Valentino,A.,Featherstone, R.M.,1961. A new and rapid colorimetric determination of acetylcholinesterase activity. Biochem. Pharma - col.7, 88-95.

22. Vos G, Sachsse K. Red cell and plasma cholinesterase activities in micro samples of human and animal blood determined simultaneously by a modified acetylthiocholine/DTNB procedure. Toxicol Appl Pharmacology. 1970; 16:764772

23. La Fratta, I., Tatangelo, R., Campagna, G. et al. The plasmatic and salivary levels of IL-1 $\beta$, IL-18 and IL-6 are associated to emotional difference during stress in young male. Sci Rep 8, 3031 (2018).

24. Zhang $H$, Sui JN, Gao L, Guo J. Subcutaneous administration of infliximabattenuated silica-induced lung fibrosis. Int J Occup Med Environ Health. 2018;31(4):503-515.

25. Mannari C, Origlia N, Scatena A, et al. BDNF level in the rat prefrontal cortex increases following chronic but not acute treatment with duloxetine, a dual acting inhibitor of noradrenaline and serotonin re-uptake. Cell Mol Neurobiol. 2008;28(3):457-468.

26. Liu MY, Wei WL, Stone CR, Zhang LJ, Tian GX, Ding JN. Beneficial effects of trimetazidine on expression of serotonin and serotonin transporter in rats with myocardial infarction and depression. Neuropsychiatr Dis Treat. 2018;14:787797

27. Tekula MR, Sunand K, Begum N, Kakalij RM, Bakshi V. Neuroprotective Effect of Resveratrol on Valproic Acid-Induced Oxidative Stress Autism in Swiss Albino Mice. Int. J. Pharm. Sci. Drug Res. 2018; 10(3):103-110.

28. Ruhela RK, Soni S, Sarma P, Prakash A, Medhi B. Negative geotaxis: An early age behavioral hallmark to VPA rat model of autism. Ann Neurosci. 2019;26(1):25-31.

29. Schneider T, Turczak J, Przewłocki R. Environmental enrichment reverses behavioral alterations in rats prenatally exposed to valproic acid: issues for a therapeutic approach in autism Neuropsychopharmacology. 2006; 31:36-46.

30. Molloy CA, Morrow AL, Meinzen-Derr J, Schleifer K, Dienger K, ManningCourtney $\mathrm{P}$, Altaye M, Wills-Karp M. Elevated cytokine levels in children with autism spectrum disorder. J Neuroimmunol. 2006; 172:198-205.

31. Jyonouchi $\mathrm{H}$, Sun S, Itokazu N. Innate immunity associated with inflammatory responses and cytokine production against common dietary proteins in patients with autism spectrum disorder. Neuropsychobiology. 2002; 46:76-84. 
32. Wei, Hongen, et al. "IL-6 is increased in the cerebellum of autistic brain and alters neural cell adhesion, migration, and synaptic formation." Journal of neuroinflammation vol. 8 52. 19 May. 2011.

33. Singh VK. Plasma increase of interleukin-12 and interferon-gamma. Pathological significance in autism. J Neuroimmunol. 1996; 66:143-145.

34. Miyazaki K, Narita N, Sakuta R et al. Serum neurotrophin concentrations in autism and mental retardation: A pilot study. Brain Devel. 2004; 26:292-295.

35. Croen LA, Goines P, Braunschweig D, et al. Brain-derived neurotrophic factor and autism: maternal and infant peripheral blood levels in the Early Markers for Autism (EMA) Study. Autism Res. 2008;1(2):130-137.

36. Mannari C, Origlia N, Scatena A, et al. BDNF level in the rat prefrontal cortex increases following chronic but not acute treatment with duloxetine, a dua acting inhibitor of noradrenaline and serotonin re-uptake. Cell Mol Neurobiol. 2008;28(3):457-468.

37. Gaspar P, Cases O, Maroteaux L. The developmental role of serotonin: news from mouse molecular genetics, Nat. Rev. Neurosci. 4 (12) (2003) 1002-1012.

38. Homberg JR, Kolk SM, Schubert D. Editorial perspective of the Research Topic Deciphering serotonin's role in neurodevelopment, Front Cell. Neurosci. 7 (2013) 212

39. Anderson GM, Horne WC, Chatterjee D, Cohen DJ. The hyperserotonemia of autism. Ann NY Acad Sci. 1990;600:331-342.
40. Tanaka, M., Sato, A., Kasai, S. et al. Brain hyperserotonemia causes autismrelevant social deficits in mice. Molecular Autism 9, 60 (2018).

41. Janusonis, Skirmantas. "Origin of the blood hyperserotonemia of autism." Theoretical biology \& medical modelling vol. 5 10. 22 May. 2008.

42. Pepeu G, Giovannini MG (2004). Changes in acetylcholine extracellular levels during cognitive processes. Learn Mem 11: 21-27.

43. Arnold H, Burk J, Hodgson E, Sarter M, Bruno J (2002). Differential cortica acetylcholine release in rats performing a sustained attention task versus behavioral control tasks that do not explicitly tax attention. Neuroscience 114 451-460.

44. Ragozzino ME, Pal SN, Unick K, Stefani MR, Gold PE (1998). Modulation of hippocampal acetylcholine release and spontaneous alternation scores by intrahippocampal glucose injections. J Neurosci 18: 1595-1601.

45. Avale ME, Chabout J, Pons S, Serreau P, Chaumont FD, Olivo-Marin J-C et al (2011). Prefrontal nicotinic receptors control novel social interaction between mice. FASEB J 25: 2145-2155.

46. McConville BJ, Sanberg PR, Fogelson MH, King J, Cirino P, Parker KW et a (1992). The effects of nicotine plus haloperidol compared to nicotine only and placebo nicotine only in reducing tic severity and frequency in Tourette's disorder. Biol Psychiatry 31: 832-840.

47. Karvat, G., Kimchi, T. Acetylcholine Elevation Relieves Cognitive Rigidity and Social Deficiency in a Mouse Model of Autism. Neuropsychopharmacol 39 831-840 (2014).

\section{GRAPHICAL ABSTRACT}

\section{HUMAN GUT MICROBIOTA- THE FORGOTTEN ORGAN}

Modulation of Dysbiotic gut to Eubiotic gut by Probiotics

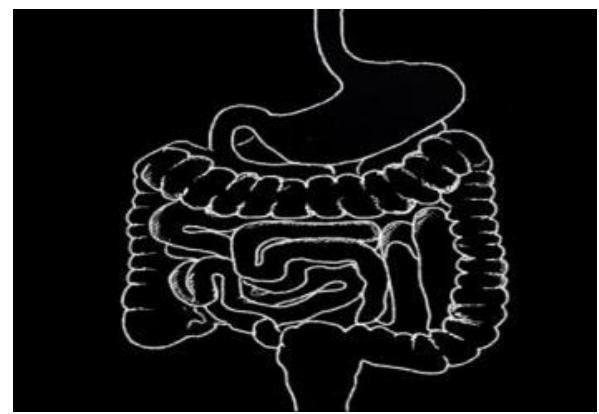

Lack of good bacteria

Altered behavior, cognition \& emotions

Altered levels of inflammatory mediators mediators

Decreased production of SCFA (Butyrate)

Altered N.T (5-HT, GABA, NA, Dopamine)

GIT complications (motility/secretions)

Increased stress(Cortisol)

Decreased Essential nutrients absorption

Dysbiotic Gut (VPA)

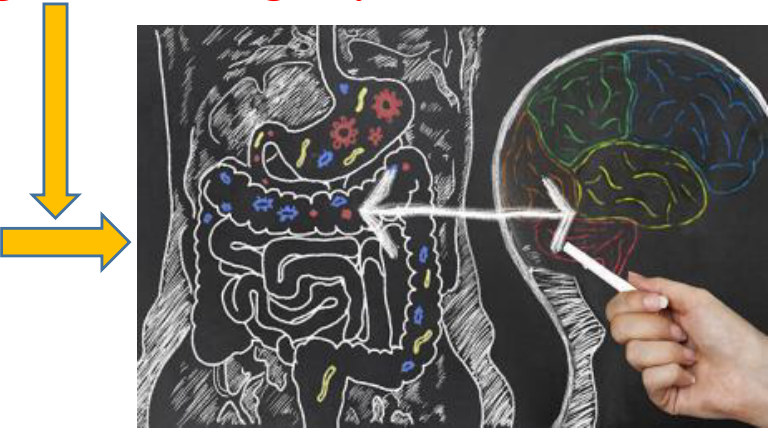

$\widehat{~ P r o b i o t i c ~ e n r i c h m e n t ~}$

Normal behavior, cognition

Healthy levels of inflammatory

Increased production of SCFA (Butyrate)

Balanced N.T (5-HT, GABA, NA, DA)

Healthy/Perfect Gut

Decreased stress(Cortisol)

Increased Essential nutrients absorption

Eubiotic Gut (Lactobacillus) 


\section{ABOUT AUTHORS}

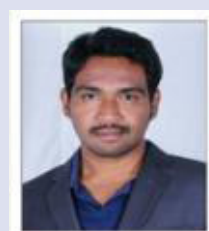

K. Sunand: Assistant Professor, Centre for Neuroscience, Department of Pharmacology, Anurag Group of Institutions. He is pursuing a Doctorate at JNTUH. He has expertise in animal experimentation, his main domains of research are Neuroscience (Autism, Depression, Motor disorders, Alzheimer's and Cerebral ischemia), PCOS, Probiotics. His current research work on Gut microbiota role in brain health. He is the Life member of IPS, APTI Professional bodies, and also a member of IAEC.

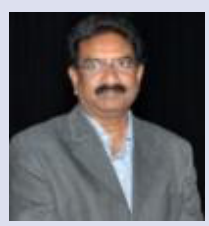

Dr. G.Krishna Mohan: Professor, Center for Pharmaceutical Sciences, Institute of Science \& Technology (IST), JNTUH. He has 4 Patents and many publications over Elsevier, Scopus Journals. He guided many Ph. D Students. His research domains are Anti-diabetic activity of various traditionally used medicinal plants, Evaluation of Immunomodulatory activity of various traditionally used medicinal plants, Isolation of bioactive phytochemical agents, Green synthesis of nanoparticles for development of NDDS.

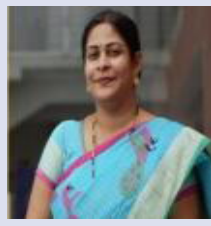

Dr. Vasudha Bakshi: Dean, School of Pharmacy has 18 years of Academic experience. She has more than 100 research publications \& 4 Patents. She organized various National \& International Conferences, Workshops, Faculty development programs. She delivered lectures in many National \& International conferences, FDPs. She is a member of PCI Inspectors. She is the Life member of IPS, IPA, APTI Professional bodies. She is the Chairman/ Member Secretary IAEC.

Cite this article: Sunand K, Mohan G, Bakshi V. Supplementation of Lactobacillus Probiotic Strains Supports Gut-Brain-Axis and Defends Autistic Deficits Occurred by Valproic Acid-Induced Prenatal Model of Autism. Pharmacogn J. 2020;12(6)Suppl:1658-69. 